\title{
THE NATURE OF CIRCULATORY COLLAPSE INDUCED BY SODIUM NITRITE ${ }^{1}$
}

\author{
By SOMA WEISS, ROBERT W. WILKINS, AND FLORENCE W. HAYNES \\ (From the Thorndike Memorial Laboratory, Second and Fourth Medical Services (Harvard), \\ Boston City Hospital, and the Department of Medicine, Harvard Medical School, Boston)
}

(Received for publication September 2, 1936)

The study to be reported was undertaken with the purpose of throwing light on the mechanism of vasomotor collapse in man. During a previous investigation (1), it was noted that small doses of sodium nitrite, which in normal subjects would produce no symptoms and slight if any circulatory changes in the prone position, would in the upright position lead to progressive vasomotor collapse, often terminating in syncope. Return to the prone position was followed by immediate recovery without ill effects. By varying the dose of sodium nitrite and the angle of tilting the body, the duration as well as the degree of the circulatory collapse could be regulated. This method, then, offered an opportunity of recording observations on vasomotor collapse under well-controlled experimental conditions. This seemed particularly desirable in view of the fact that the study of vasomotor collapse, as it occurs in various diseases, is difficult because it develops unexpectedly in seriously ill patients and often terminates fatally.

\section{METHOD}

Our primary aim was to observe simultaneously several aspects of the peripheral circulation before, during and after recovery from vasomotor collapse. The heart rate was counted by arterial palpation, by auscultation over the precordium, or from the pulse waves on the plethysmographic tracings. The arterial blood pressure was determined in the upper arm at heart level by the usual auscultatory method, using a mercury manometer. The arterial blood pressure and the pulse volume were registered by sphygmometric oscillometers.

The venous pressure was measured in the foot by the indirect method of Krogh, Turner and Landis (2). In some experiments the pressure in the femoral vein was determined by direct venous puncture, after the method of Moritz and von Tabora (3). All measurements are given in relation to the right auricle (second costal interspace). The skin temperature of the hands and feet was taken by means of a thermocouple.

1 This investigation was aided in part by a grant from the Josiah Macy, Jr., Foundation.
The blood flow through the hands was measured by the plethysmographic method of Hewlett and Van Zwaluwenburg (4) as modified by Freeman (5). The average of 5 to 10 determinations was taken for each flow. The plethysmographs were arranged on adjustable stands which allowed free movement up or down as the subject was tilted. Usually the blood flow was determined through one hand at a temperature of $32^{\circ} \mathrm{C}$., and through the other at $45^{\circ} \mathrm{C}$. At $32^{\circ} \mathrm{C}$. the physiological play of the vasomotor reflexes and other local vascular factors was maintained, whereas at $45^{\circ} \mathrm{C}$. practically all the vasoconstrictor reflexes were eliminated, and as a result of complete vascular dilatation the maximal or potential blood flow was registered. The blood flow at $45^{\circ}$ C. can thus be considered as an index of the cardiac output. In addition, we have determined by the method of Van Slyke and Neill (6) the femoral arterial and venous blood gases. The samples were taken and delivered under oil, and duplicate or triplicate determinations were made on each sample. The femoral arteriovenous oxygen difference under certain conditions is an index of the blood flow through the legs (7). Electrocardiograms were taken using the three standard leads and the fifth lead of Wolferth and Wood (8). In some experiments the respiration was recorded by means of a Marey pneumograph.

When it was not feasible to obtain all the observations described above in a single experiment, the remaining observations were completed under identical conditions on another day.

Seven young adult subjects with normal cardiovascular systems were studied systematically. Isolated observations have been made in an additional larger group on certain aspects of collapse after nitrite. At least one hour after a meal the subject was placed on a tilting table in a horizontal position, and after all the apparatus had been adjusted he was allowed to rest from 45 to 60 minutes. The study of each subject consisted in the following procedures carried out on different days. After first obtaining resting values in the horizontal position, observations were made upon (1) the effects of elevation to an upright position $\left(75^{\circ}\right)$ for 45 minutes or longer, followed by a return to the prone position; (2) the effect of oral administration of 0.12 to 0.18 grams ( 2 or 3 grains) of sodium nitrite in the horizontal position for one hour; (3) the effect of the same amount of sodium nitrite followed in 10 to 20 minutes by elevation to the upright position. While in the upright position the subjects were urged to remain motionless. At the height of the vasomotor collapse, which was usually 
associated with syncope, the subject was promptly brought back to the horizontal position and the observations were usually continued up to an hour.

\section{RESULTS}

The symptoms and clinical signs exhibited, as well as the changes observed in the cardiovascular system, were remarkably uniform in all subjects. The only essential 'variation in different persons consisted in the amount of nitrite and the subsequent duration of standing required to produce complete collapse of the circulation. The susceptibility to vasomotor collapse did not necessarily depend on the physical state. Some of the robust and physically trained subjects developed vasomotor collapse and syncope promptly after relatively small amounts of nitrite.

The series of observations made on D. M., a tall, robust subject of 28 years, serve to illustrate the results obtained on all subjects. Figure 1 presents the response to the upright position without nitrite. The maximal blood flow (at $45^{\circ} \mathrm{C}$.) through the hand remained essentially unaltered. The arterial pulse pressure became somewhat smaller as a result of the slight fall in the systolic and the rise in the diastolic pressures, which is the physiological response to standing. The venous pressure in the foot became elevated and later showed a moderate though progressive fall, but remained above the hydrostatic level of the heart. The heart rate increased. The subject remained symptom free. After the return to the horizontal position the circulatory measurements resumed their previous values.

Figure 2 presents the responses of the same subject, while remaining in the horizontal position, to 0.18 gram ( 3 grains) of sodium nitrite. There was slight, if any, fall in the potential blood flow to the hand, no essential change in the arterial

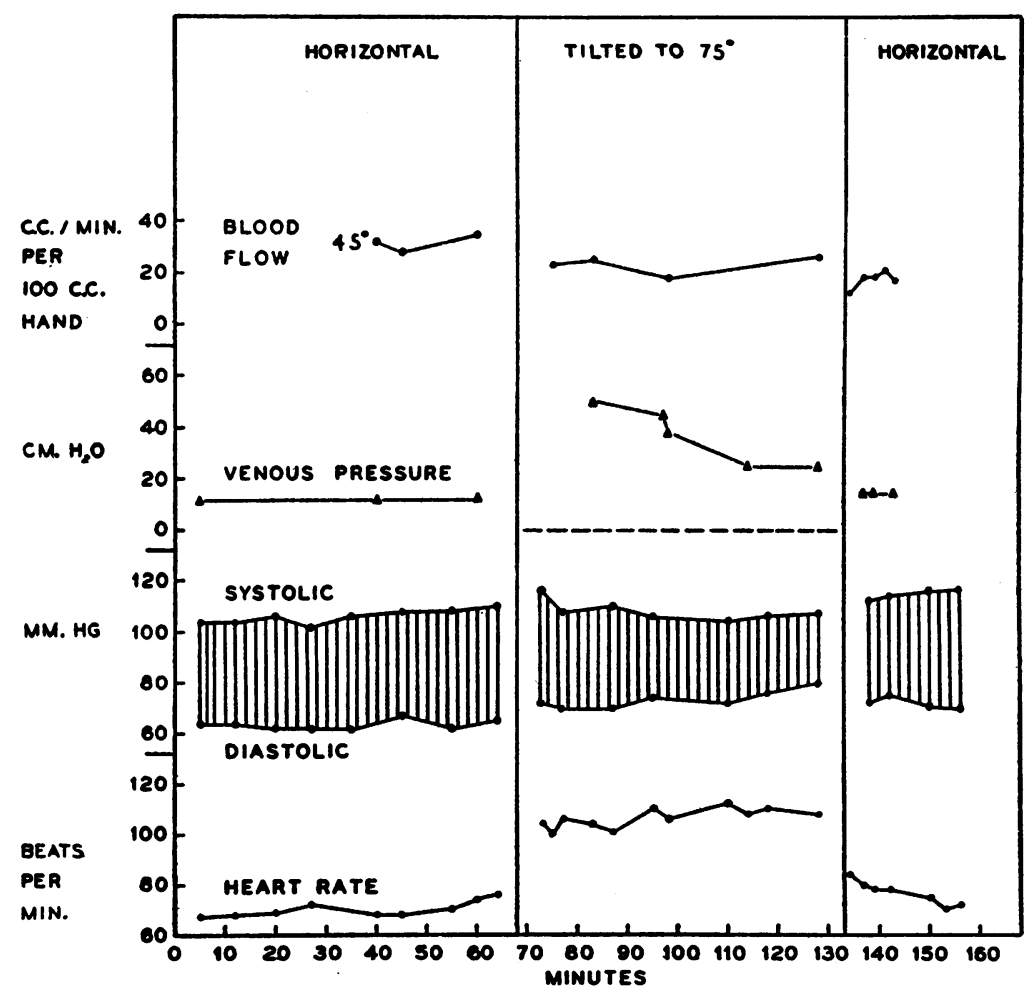

Fig. 1. Subject D. M. Effect of Tilting to $75^{\circ}$ on the Blood Flow through the Hand at $45^{\circ} \mathrm{C}$., on the Venous Pressure in the Foot, the Arterial Blood Pressure and Heart Rate.

All measurements of venous pressure are given in relation to the level of the right auricle (second costal interspace). 


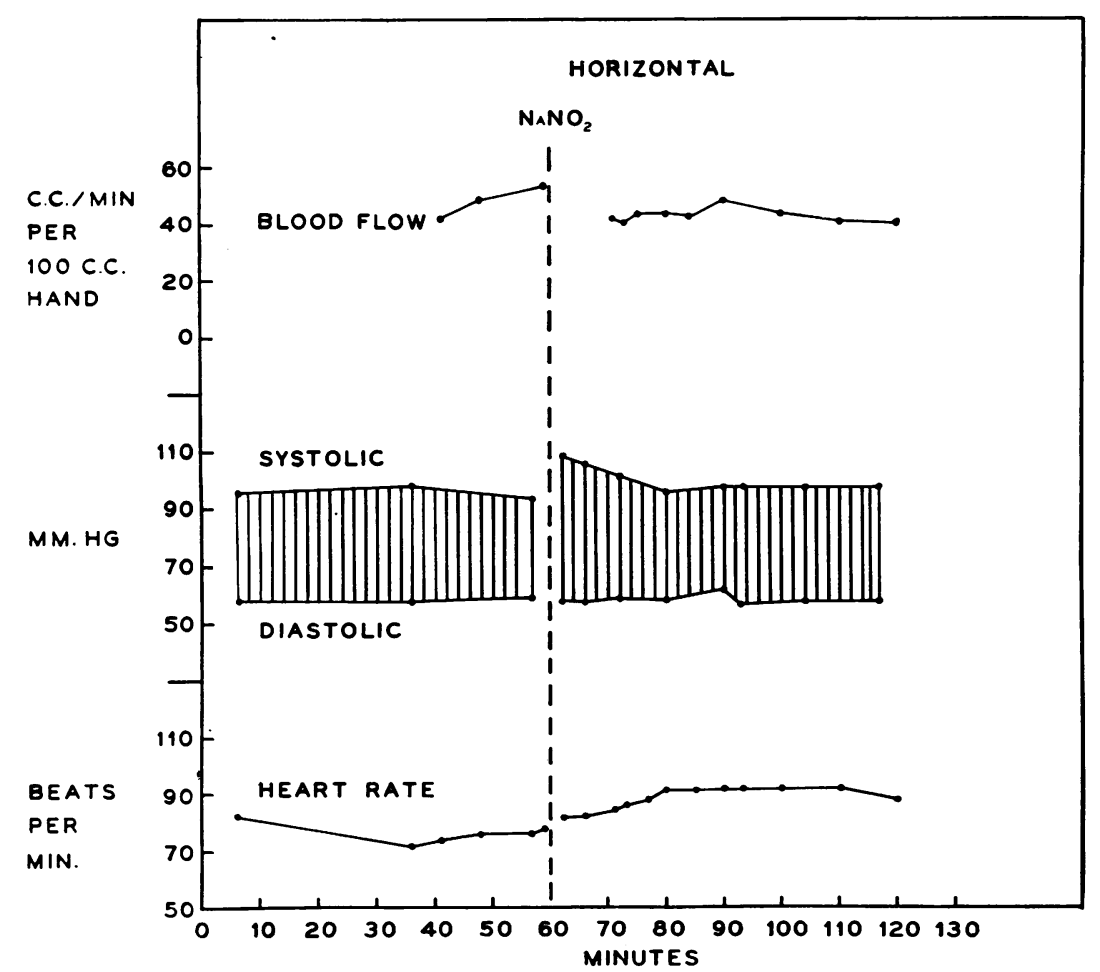

Fig. 2. Slbject D. M. Effect of 0.18 Gram of Sodium Nitrite on the Blood Flow through the Hand at $45^{\circ}$ C., on the Arterial Blood Pressure and the Heart Rate.

pressure, and only a very slight rise in the heart rate. There were no subjective symptoms.

Figure 3 demonstrates his responses after the same oral dose of nitrite and subsequent elevation to the upright position. Ten minutes after the ingestion of nitrite and while still in the horizontal position, there was again only a slight fall in the blood flow and moderate rise in the cardiac rate. Following elevation, however, marked changes occurred in rapid succession. For about 5 minutes the subject remained symptom free. Thereafter he yawned occasionally, the intervals between yawns becoming progressively shorter toward the end of the standing period. The respirations became deeper and at times assumed the character of sighing. He became restless. Belching and increase in peristaltic sounds appeared. First warm and later cold perspiration broke out over the face and extremities, and finally it became beaded and profuse over the entire surface of the body. The skin became first slightly cyanotic and in about 20 minutes it was ashen grey.
The subject appeared drowsy. The pupils were dilated. At this point the picture corresponded in every respect to clinical vasomotor collapse.

The moderately lowered blood flow, which developed right after the tilting, was well maintained until shortly before complete collapse and syncope, when it rapidly fell to zero. The blood flow became more and more influenced by the deep respiration, as well as by the sighing and yawning. The arterial pulse pressure became quite narrow soon after tilting, mainly as a result of a fall in the systolic pressure. The diastolic pressure was well sustained. The pulse at the wrist became small and thready, while the carotid pulsation was still good. Finally, the radial pulse became imperceptible. It was of interest to note that after each yawn or sigh the pulse was instantly restored, to disappear again after several beats. The occurrence of yawning or sighing could often be foretold from the preceding disappearance of the pulse. The venous pressure throughout the standing fell rapidly until it 


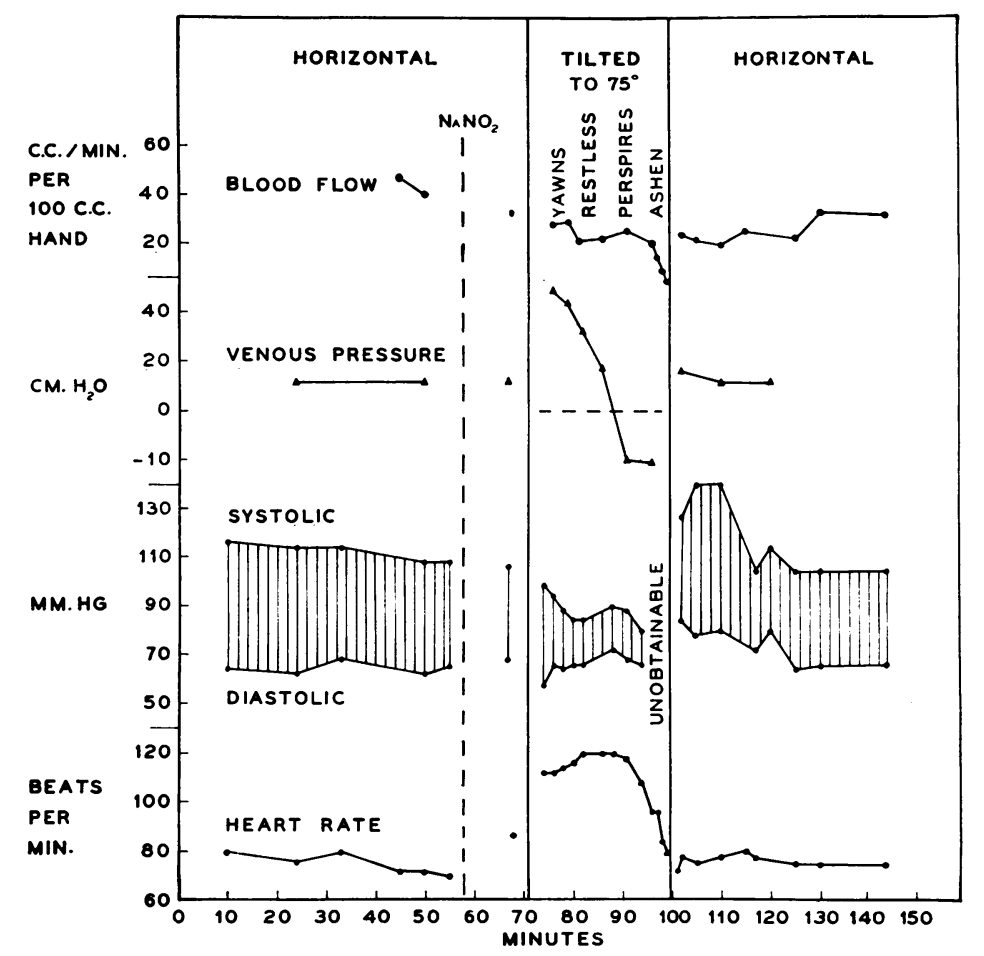

Fig. 3. Subject D. M. Effect of Administration of 0.18 Gram of Sodium Nitrite, Followed by Tilting to $75^{\circ}$, on the Blood Flow throvgh the Hand at $45^{\circ}$ C., on the Venous Pressure in the Foot, the Arterial Blood Pressure and the Heart Rate.

After 29 minutes at $75^{\circ}$ the subject fainted. All measurements of venous pressure are given in relation to the right auricle.

reached a level which was below the hydrostatic level of the right auricle. This indicates that the column of blood in the inferior vena cava stood at a level below the right auricle. The rate of the heart became rapid and remained at about 120 per minute until shortly before the syncope, when it slowed markedly to about 80 . At this time the blood pressure was not obtainable. Finally, the vision became dim and manifestations of loss of muscular power and of unconsciousness appeared, whereupon the patient was immediately returned to the horizontal position. Within 15 to 20 seconds he regained consciousness and all symptoms subsided.

Coincident with the rapid subjective improvement after a return to the horizontal position, all aspects of the circulation also promptly returned to normal. The systolic and diastolic blood pressure, in spite of the normal heart rate, actually became temporarily elevated.
The plethysmographic blood flow and respiratory tracings of P. C., a 29-year-old subject, are presented on Figure 4. The symptoms and signs of this subject, who received 0.18 gram ( 3 grains) of sodium nitrite and was then tilted upright, were essentially the same as those described above. In the prone position the blood pressure and the maximal blood flow (at $45^{\circ}$ C.) through the hand showed no change after the administration of nitrite. After elevation to the upright position the pulse pressure became small and the pulse rapid and thready. The venous pressure fell and reached a negative level before syncope. Two minutes before the fainting the blood flow was still about 60 per cent of the original level, in spite of a pulse pressure of only $16 \mathrm{~mm}$. $\mathrm{Hg}$ and a cardiac rate of 154 per minute. Thirty seconds before fainting, however, no blood flow or arterial pressure was obtainable. The respirations became deep and rapid and the cardiac rate slowed 


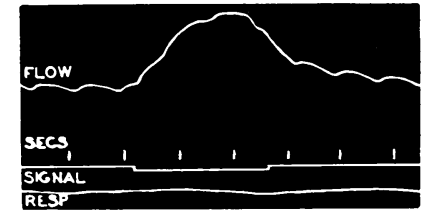

I. HORIZONTAL BEFORE NITRITE

FLOW-39.2 R.-18 B.P.-110/70 P-78

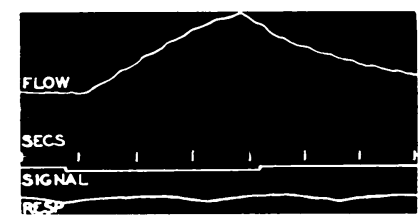

3. TILTED $75^{\circ} 2$ MIN. BEFORE FAINTING FLOW-22.7 R-21 B.P.-86/70 P.-154

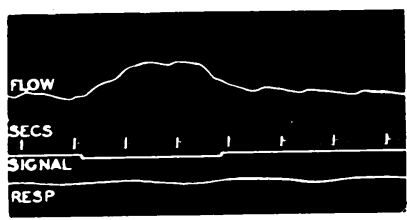

5. HORIZONTAL I MIN. AFTER FAINTING FLOW-18.4 R-20 B.P.-104/72 P.-60

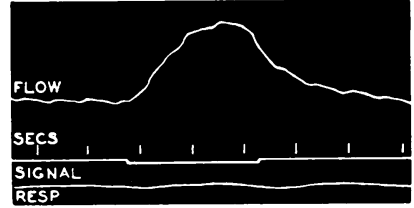

2. HORIZONTAL 10 MIN. AFTER NITRITE FLOW-38.6 R-21 B.P.-112/72 P.-90

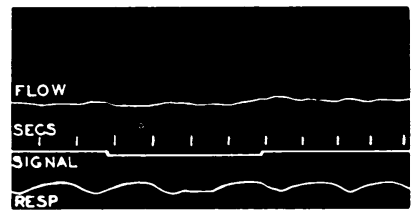

4. TILTED $75^{\circ} \mathrm{Y} / 2$ MIN. BEFORE FAINTING FLOW-? R:-32 B.P.? P-66

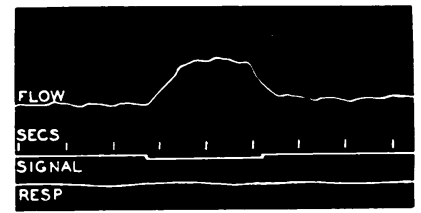

6. HORIZONTAL 45 MIN. AFTER FAINTINC FLOW-30.3 R-20 B.P.-106/72 P.-80

Fig. 4. Sebject P. C. Plethyshographic Recoris of Blood Flow ix the Haxd at $45^{\circ}$ C. and Respiratory Tracings after 0.18 Gran of Sodicil Nitrite, Followed by Tiltixg to $75^{\circ}$.

After 16 minutes at $75^{\circ}$ the subject fainted.

abruptly to 66 . Within 25 minutes after resuming the horizontal position the blood flow returned to normal.

Because of the slowing of the heart rate just before syncope, the question arose as to whether the late and sudden fall in blood flow. and hence the final syncope, depended on this cardiac slowing. The experiment outlined on Figure 3 was therefore repeated with the intramuscular administration of $2 \mathrm{mgm}$. of atropine sulphate. This eliminated the cardiac slowing without. however. altering the manifestations of vasomotor collapse. In the light of this fincling. it is our contention that cardiac slowing is a secondary manifestation and is dependent on stimulation of the vagus centers by cerebral anoxemia. The degree of vagal manifestations varied in different subjects, and in some was not present eren though fainting occurred.

The olsservations made on S. M.. a 19-year-old subject, are typical of those experiments in which the blood flow was measured simultaneously in both hands. Figure 5 represents the response to tilting without nitrite. The blood flow in the hand at $32^{\circ} \mathrm{C}$.. as expected. was slower than in the warm hand $\left(45^{\circ} \mathrm{C}\right.$.) and showed a somewhat greater decrease with tilting, presumably due to vasoconstriction. Lltimately, however, the flow became about the same in both hands. Is inclicated in Figure 6, in the dilated hand the maximal flow decreased after nitrite. while it remained the same in the cooler hand with normal vasomotor regulation. Figure 7 shows the responses after 0.12 gram (2 grains) of nitrite. followed by tilting. Here the blood flow in the dilated hand showed a consiclerable decrease immediately after tilting. while in the hand with normal vasomotor regulation it became unusually slow, as a result of vasoconstriction. On returning the subject to the horizontal position, the rise in the cool hand was particularly rapicl, reaching the level of the maximal flow, indicating an active vasodilatation in the cool hand. These responses exemplify the observations mate in this and in other stuclies 


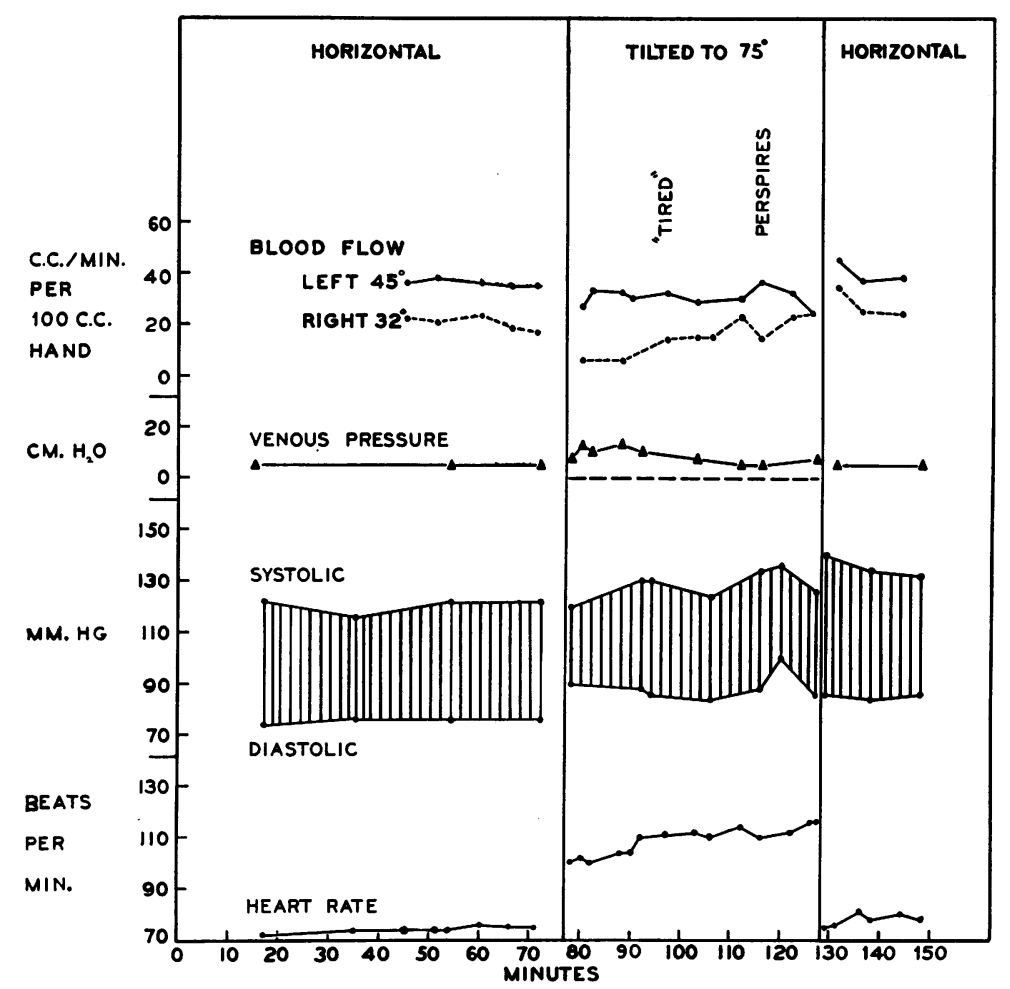

Fig. 5. Subject S. M. Effect of Tilting to $75^{\circ}$ on the Blood Flow through the Hands, One at $45^{\circ}$ C. and the Other at $32^{\circ} \mathrm{C}$., on the Venous Pressure in the Foot, the Arterial Blood Pressure and the Heart Rate. auricle.

All measurements of venous pressure are given in relation to the right

that the cool hand with normal vasomotor regulation shows greater spontaneous variations in blood flow than the dilated hand. Spontaneous vasoconstrictor responses were frequently noted in the cool hand during tilting. The rest of the circulatory changes, as well as the other manifestations of vasomotor collapse, were similar to those described in the first subject. Although, in Subject S. M., syncope developed as soon as 12 minutes after. the tilting, in some subjects the manifestations of collapse without syncope have been maintained for as long as an hour or more by varying the close of nitrite and the degree of tilting.

In order to ascertain the effect of nitrite and tilting on the blood flow in the legs, the femoral arteriovenous oxygen difference was determined at different times under the experimental conditions described above. Table I presents the re-
TABLE I

Effect of 0.18 gram of sodium nitrite, followed by tilting to $75^{\circ}$, on the arteriovenous oxygen difference of the femoral blood of Subject $P$. $C$.

\begin{tabular}{|c|c|}
\hline & $\begin{array}{l}\text { Volumes } \\
\text { per cent }\end{array}$ \\
\hline 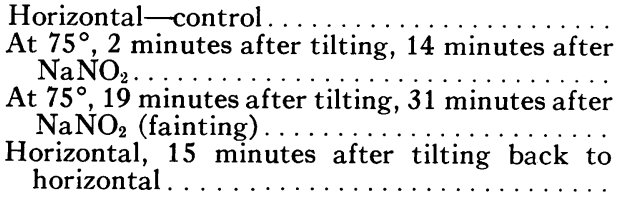 & $\begin{array}{r}5.79 \\
7.59 \\
12.26 \\
7.58\end{array}$ \\
\hline
\end{tabular}

sults of a typical experiment. As indicated, the oxygen difference, and hence the blood flow, decreased slightly soon after the tilting and reached a level of 12.26 volumes per cent at the time of the fainting. The degree of slowing, however, is not unusual, because similar values have been obtained in control observations after standing only (7). 


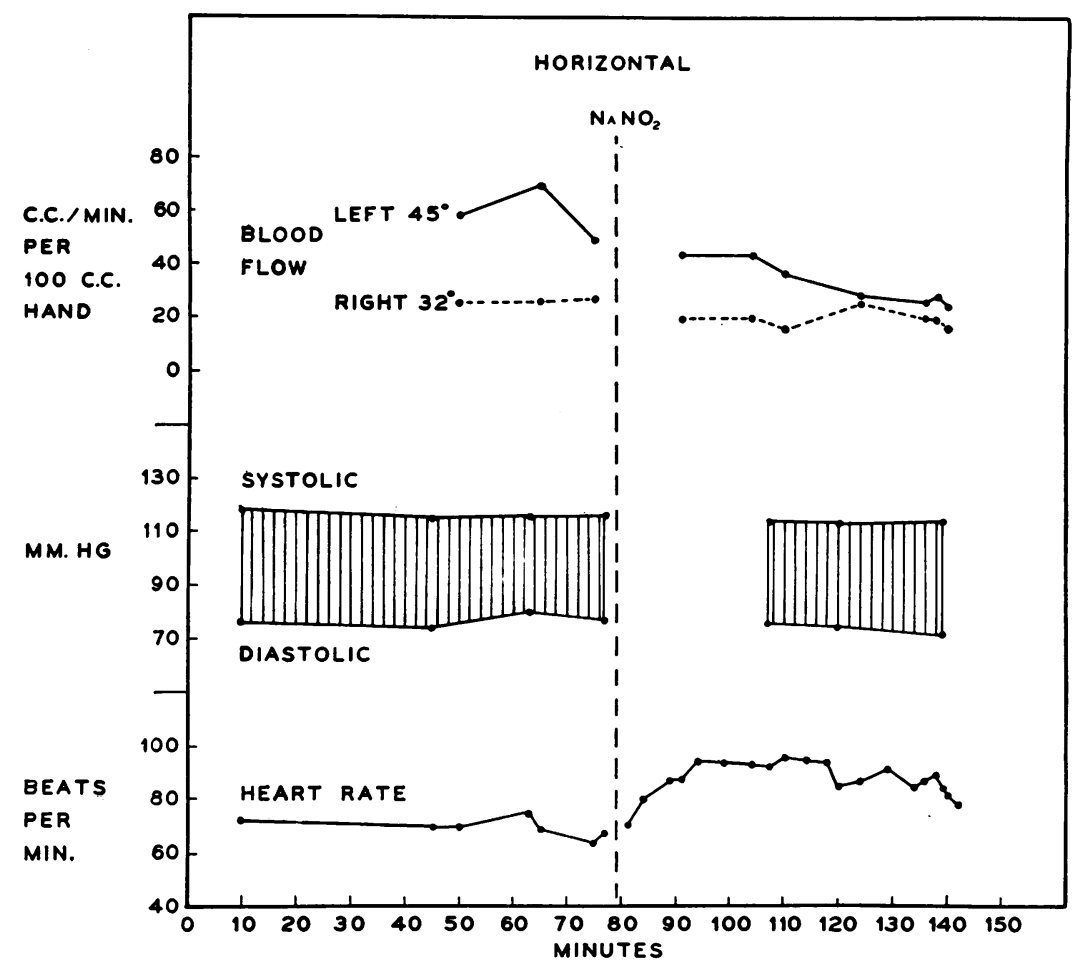

Fig. 6. Subject S. M. Effect of 0.12 Gram of Sodium Nitrite on the Blood Flow through the Hands, One at $45^{\circ}$ C. and the Other at $32^{\circ}$ C., on the Arterial Blood Pressure and the Heart Rate.

The pulse volumes, as measured with oscillometers, revealed a perceptible increase after the administration of nitrite, with the subject in the prone position, an observation which is in accord with the known effect of nitrite on the larger arteries (1). After tilting, with or without nitrite, there was a decrease in the arterial pulse volumes of both the arm and the leg. This decrease paralleled the pulse pressure and the character of the pulse by palpation.

The changes in the skin temperature were variable, even though care was taken to maintain constant room temperature, and repeated observations were made. We were unable to correlate these changes with any of the other measurements of the circulation. In some of the experiments, a fall in skin temperature was found on standing, but this was not uniformly true.

In view of the small brachial pulse pressure, rapid heart rate and markedly decreased flow through the hand toward the end of the vasomotor collapse, it became of interest to ascertain whether the electrocardiogram would reveal any changes indicating anoxemia of the heart. It was rather unexpected to find that the changes, even during the height of the collapse, were but slight and mainly in the fifth lead, consisting of considerably increased amplitude of the $T$ wave, slightly out of proportion to the increased rate, as indicated in Figure 8. This absence of change in the electrocardiographic complexes is in harmony with lack of symptoms referable to cardiac anoxemia.

\section{DISCUSSION}

In this study, a correlation has been made between a group of clinical symptoms and signs and the technical measurements of the cardiovascular system and the circulation. The syndrome presented by the subjects was identical with that exhibited by patients with a pronounced degree of vasomotor collapse, such as is apt to occur in pneumonia and other infectious diseases, in anaphylactic shock, abdominal perforation and in 


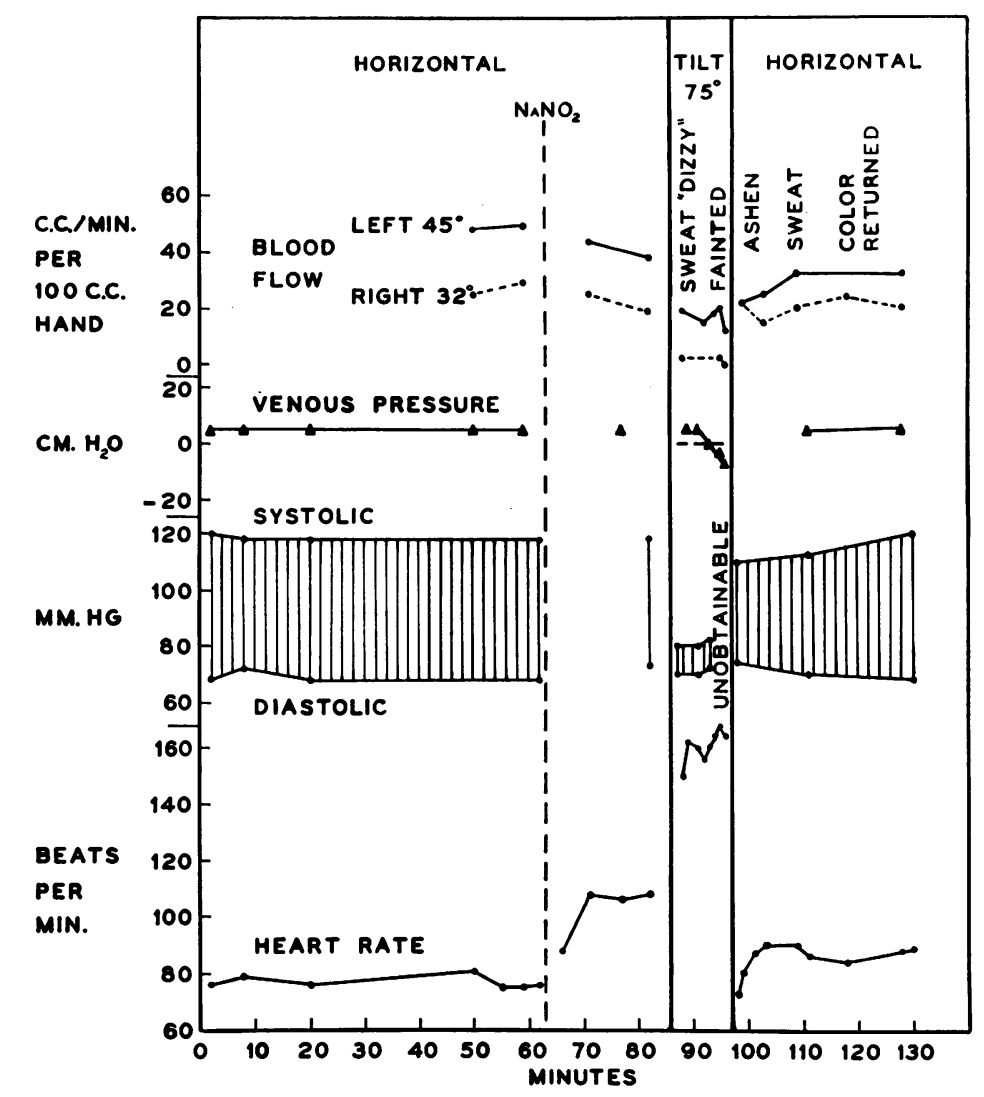

Fig. 7. Subject S. M. Effect of 0.12 Gram of Sodium Nitrite Followed by Tilting to $75^{\circ}$ on the Blood Flow through the Hands, One at $45^{\circ} \mathrm{C}$. and the Other at $32^{\circ} \mathrm{C}$., on the Venous Pressure in the Foot, the Arterial Blood Pressure and the Heart Rate.

All measurements of venous pressure are given in relation to the right auricle.

other conditions. The significance of the study lies in the fact that continuous observations have been made on several aspects of the circulation in subjects with normal cardiovascular and nervous systems, during the induction of collapse by an agent which exerts no primary effect on the heart. Peripheral failure of the circulation was studied, therefore, in its pure form under controlled conditions.

The primary changes in the circulation, which always preceded the symptomatic manifestations of collapse, consisted in tachycardia, small arteriai pulse pressure with small pulse volume (thready pulse), fall in the venous pressure and arteriolar vasoconstriction, as indicated by moderately decreased blood flow of the cool, but not of the warm, hand. The small pulse pressure was caused mainly by a fall in the systolic pressure, with fairly well maintained or even elevated diastolic pressure. Fall in the diastolic pressure was observed during the advanced state of collapse. It is of particular significance that in the presence of these circulatory changes the maximal blood flow was but moderately decreased, and the subject remained free of symptoms. As the above described circulatory changes continued, however, symptoms of collapse appeared which were associated with a progressive decrease in the maximal blood flow. When it had decreased to from 20 to 40 per cent of its normal value, pronounced manifestations of circulatory collapse developed, although consciousness and other vital bodily re- 


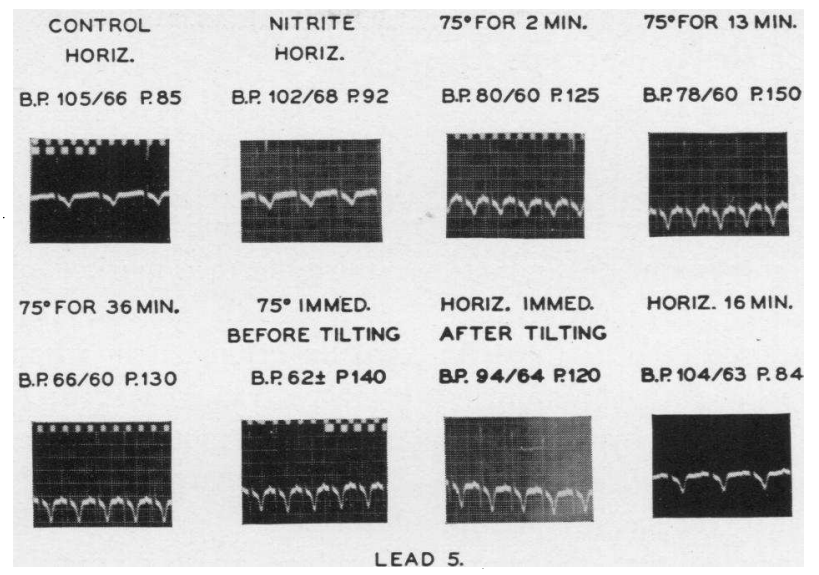

Fig. 8. Subject D. M. Electrocardiographic Records after the Administration of 0.18 Gram of Sodium Nitrite, Followed by Tilting to $75^{\circ}$.

Subject remained at $75^{\circ}$ for 52 minutes, at the end of which he felt weak and dizzy.

sponses were still maintained. Further diminution of the blood flow finally led to fainting, usually associated with rapid fall of the diastolic as well as of the systolic pressure. This syncope exhibited all the characteristics of the vasovagal type $(9,10)$.

The collapse studied furnishes an example of a bodily state in which nervous manifestations arise secondarily to changes in the vascular system. The marked elevation of the cardiac rate, the change in arterial pressure and the vasoconstrictor response observed in the hand occurred practically instantaneously after the tilting and before the appearance of subjective symptoms. The elevation of the cardiac rate, which in some cases attained a level of 140 to 160 per minute, and the vasoconstrictor response are attributed to the stimulating effect of the lowered systolic pressure on the carotid sinus and aortic depressor reflex mechanisms. Lowering of the arterial pressure in these two vascular areas induces a nervous response leading to tachycardia and vasoconstriction, as has been shown by Hering (11), Heymans (12) and others. The changes observed subsequently are attributed to a progressively increasing ischemia of the medullary centers. It is of particular interest to note that at this time hyperactivity of both sympathetic and parasympathetic functions occurred simultaneously, although with the approach of maximal medullary ischemia the parasympathetic manifestations became predominant. Thus tachycardia, vasoconstriction and dilatation of the pupils were observed simultaneously with sweating, yawning, belching, nausea, cramps (indicating pyloric spasm) and increased peristalsis. Just before the onset of syncope, bradycardia often appeared. This bradycardia and some of the other evidences of parasympathetic overactivity are considered as secondary phenomena to the collapse and syncope, since the latter syndromes occurred in some subjects without these parasympathetic manifestations. Furthermore, atropine abolishes the bradycardia without essentially influencing the course of collapse and syncope.

From our data and from what we know of experiments on animals it is impossible to state whether this simultaneous overactivity of both the sympathetic and parasympathetic systems depends entirely upon increasing medullary ischemia stimulating both types of centers directly, or upon a combination of this effect and the action of the aortic and carotid sinus depressor reflexes. In response to the drop in systolic pressure, the latter reflexes induce overactivity of certain sympathetic functions, and at the same time inhibition of parasympathetic functions. The simultaneous advanced ischemia of the medulla acts as a powerful 
stimulus to the vagal (parasympathetic) centers, which would partially or completely overcome the inhibitory influence of the carotid sinus and aortic reflexes, resulting in the simultaneous parasympathetic overactivity observed.

The manifestations of increasing cerebral ischemia in man here described correspond to findings in animals. Kisch and Sakai (13), Anrep and Segall (14), without full appreciation of the rôle of the vascular reflexes, concluded that in animals cerebral ischemia produces initial tachycardia and vasoconstriction. Subsequently, the vagus center is reexcited and bradycardia or cardiac arrest follows. Heymans (15) concluded that the vagal centers of the dog are easily stimulated by acute cerebral anoxemia. The responses of the medullary centers of animals of different species, as well as of the same species under different kinds of anesthesia, may show differences $(16,17,18)$. Our observations on unanesthetized man in this and in previous studies $(19,20)$ are interpreted as indicating that under certain physiological stress or pathological conditions partial or general overactivity of both sympathetic and parasympathetic nervous systems may occur simultaneously. Such overactivity is produced by stimulation of peripheral reflexes or of the centers, or of both together.

The vasomotor collapse described by us depended on the combined effect of nitrite and tilting. The condition was precipitated by the orthostatic position of the body, and was promptly abolished by a return to the horizontal position. The fall in venous pressure and the resultant decrease in return of venous blood to the heart in the upright position must be due to a pooling of an appreciable amount of blood somewhere entirely within the vascular bed. Had there been an actual loss of a considerable amount of blood or plasma from within the vascular bed, as has been shown to occur in certain types of circulatory failure, complete recovery within such a short period of time after returning to the prone position could not have been possible. The essential feature of the vasomotor collapse induced by nitrite is, therefore, a disproportion between the circulating blood volume and the volume of the peripheral vascular bed (decrease of the "effective blood volume"). The exact mechanism by which the pooling of blood resulting in this disproportion is brought about will be discussed in a subsequent report (21).

While the vasomotor collapse here described depended on the orthostatic position, collapse of the circulation can also occur in the horizontal position, provided larger doses of nitrite are administered or a marked susceptibility exists. The latter was the case in a few individuals with arterial hypertension in whom transient collapse and syncope occurred in the horizontal position (1). Severe vasomotor collapse also follows the administration of large doses of nitrite to animals in the horizontal position. The orthostatic position, therefore, merely intensified the type of changes in the vascular system, which would occur even in the horizontal position after the administration of large doses of nitrite.

Prolonged orthostatic position alone, particularly without motion, can produce in certain healthy persons changes similar to those here described. As has been discussed in connection with postural hypotension (22), under certain physiological conditions the postural adaptation of the circulation may gradually become inadequate as standing is maintained (23). In most cases the chief cause is not a fault in the postural vascular reflexes, which are often operating excessively, but a deficient intrinsic vascular tone or poor tone in the skeletal musculature. Turner, Newton and Haynes (24) have pointed out that certain individuals consistently have a tendency to faint after a relatively short standing period. Under certain conditions, the upright posture may also lead to serious consequences (10). It is probable that the collapse studied by us could have resulted in serious sequelae had the subjects not been returned promptly to the horizontal position. That the position of the body also plays a significant rôle in clinical syncope and collapse is attested by bedside observations. These syndromes are frequently precipitated in various diseases when the patient assumes an upright position. Furthermore, manifestations of collapse, which develop in the horizontal position, may promptly subside if the return of blood to the heart and the cerebral ischemia are aided by lowering the head and elevating the lower half of the body ("Trendelenburg position").

There is an apparent similarity between the collapse studied by us and the phenomenon described 
as "Sportkrankheit" or " gravity shock" which develops if subjects who have engaged in sudden and strenuous exercise are kept immobile in the upright position. This condition, described by Jokl (25), Weltzien (26) and Mateeff and Petroff (27), has been studied recently by Mateeff (28), who claims that the condition depends on the pooling of the blood in the dilated capillary bed of the legs following exercise.

During the state of collapse the degree of ischemia was not the same in various vascular areas. At a time when the pulse was imperceptible over the radial artery it was still felt over the carotid and femoral arteries. When the maximal flow was greatly diminished in the hand, the degree of ischemia was not always markedly abnormal in the leg. The exact cause of this difference is not clear, though the distance of the area from the heart and the gravity effect must have been factors. It is also of interest that the electrocardiograms failed to reveal any appreciable amount of myocardial anoxemia. The explanation of the latter finding may lie in the possibility that the relative decrease in the coronary circulation was less than that in the extremities, and was not out of proportion to the decrease in the work of the heart, which must have been considerable. This explanation seems to be applicable to similar electrocardiographic findings in the presence of clinical syncope, collapse and shock $(18,19,29)$.

The demonstration of severe derangement of the circulation with secondary disturbances of the functions of several organs in healthy subjects with normal cardiac and vascular reserves offers a rational implication for a similar state of affairs in disease, in which there is usually an impaired nervous or cardiovascular reserve. The reason for the progressive downhill course of patients with collapse, unless the etiological factors are eliminated in time, becomes obvious.

\section{SUM MARY}

1. Sodium nitrite, in an amount which produces no symptoms and only slight if any changes in the circulation in the horizontal position, causes circulatory collapse in the immobile upright position.

2. Symptomatic manifestations of this circulatory collapse, which are identical with those in disease, have been correlated with the changes in the circulation.

3. Tachycardia, fall in the systolic pressure, small arterial pulse pressure and pulse volume, fall in the venous pressure in the foot, arteriolar constriction with a moderate or pronounced decrease in the "actual" blood flow but with only a small decrease in the "maximal" blood flow in the hands preceded the symptoms of collapse.

4. Pronounced manifestations of circulatory collapse appeared when the maximal blood flow through the hands reached a level of 20 to 40 per. cent of the normal value. Simultaneously, there was a fall in the venous pressure, usually reaching a level below that of the right auricle. Further decrease in blood flow resulted in vasovagal syncope.

5. Even in the presence of markedly decreased blood flow during collapse or syncope the complexes of the electrocardiogram revealed but minor changes.

6. Changes in the autonomic nervous system appeared as secondary manifestations to the primary action of nitrite on the peripheral vascular system. It is concluded that the simultaneous overactivity of the sympathetic and parasympathetic autonomic nervous systems arose first through peripheral vascular reflexes and subsequently through medullary ischemia.

This investigation was carried out with the technical assistance of Miss Josephine M. McIntire.

\section{BIBLIOGRAPHY}

1. Weiss, Soma, and Ellis, L. B., Influence of sodium nitrite on the cardiovascular system and on renal activity in health, in arterial hypertension and in renal disease. Arch. Int: Med., 1933, 52, 105.

2. Krogh, A., Turner, A. H., and Landis, E. M., A celluloid capsule for measuring venous pressures. J. Clin. Invest., 1932, 11, 357.

3. Moritz, F., and von Tabora, D., Uber eine Methode, beim Menschen den Druck in oberflächlichen Venen exakt zu bestimmen. Deutsches Arch. f. klin. Med., 1909-10, 98, 475.

4. Hewlett, A. W., and Van $Z$ waluwenburg, J. G., The rate of blood flow in the arm. Heart, 1909-10, $1,87$.

5. Freeman, N. E., The effect of temperature on the rate of blood flow in the normal and in the sympathectomized hand. Am. J. Physiol., 1935, 113, 384.

6. Van Slyke, D. D., and Neill, J. M., The determina- 
tion of gases in blood and other solutions by vacuum extraction and manometric measurement. I. J. Biol. Chem., 1924, 61, 523.

7. Weiss, Soma, and Ellis, L. B., Oxygen utilization and lactic acid production in the extremities during rest and exercise in subjects with normal and in those with diseased cardiovascular systems. Arch. Int. Med., 1935, 55, 665.

8. Wolferth, C. C., and Wood, F. C., The electrocardiographic diagnosis of coronary occlusion by the use of chest leads. Am. J. M. Sc., 1932, 183, 30.

9. Lewis, T., Vasovagal syncope and the carotid sinus mechanism. Brit. M. J., 1932, 1, 873.

10. Weiss, S., Syncope and Related Syndromes. Oxford Med., 1935, 2, 250 (9), Oxford University Press, New York.

11. Hering, H. E., Die Karotissinusreflexe auf Herz und Gefässe. Th. Steinkopff, Dresden und Leipzig, 1927.

12. Heymans, C., Le sinus carotidien et les autres zones vasosensibles réflexogènes. Presse Universitaires de France, Paris; H. K. Lewis \& Co., London, 1929.

13. Kisch, B., and Sakai, S., Die Änderung der Funktion der extrakardialen Herznerven infolge Änderung der Blutzirkulation. I. Die Verstärkung der Wirkung peripherer Vagusreizung durch Verschluss des aortenbogens oder der Bauchaorta und ihr zusammenhang mit der Änderung der Schlagzahe bei Aortenverschluss. Arch. f. d. ges. Physiol., 1923, 198, 65, 86.

14. Anrep, G. V., and Segall, H. N., The central and reflex regulation of the heart rate. J. Physiol., 1926, 61, 215.

15. Heymans, C., Reference (12), p. 84.

16. Norris, V. H., and Weiss, S., The pharmacological and therapeutic properties of alpha-lobelin. A comparison of its action on the respiratory center with that of other respiratory stimulants. J. Pharmacol. and Exper. Therap., 1927, 31, 43.

17: Capps, R. B., Ferris, E. B., Jr., Taylor, F. H. L., and Weiss, S., Rôle of pressor substances in arterial hypertension. Arch. Int. Med., 1935, 56, 864.
18. Weiss, S., Unpublished observations.

19. Ferris, E. B., Jr., Capps, R. B., and Weiss, S., Carotid sinus syncope and its bearing on the mechanism of the unconscious state and convulsions. A study of 32 additional cases. Medicine, 1935, 14, 377.

20. Ferris, E. B., Jr., Capps, R. B., and Weiss, S., The relation of the carotid sinus to the autonomic nervous system and to the neuroses. Arch. Neurol. and Phychiat. (In press).

21. Wilkins, R. W., Haynes, F. W., and Weiss, S., The rôle of the venous system in circulatory collapse induced by sodium nitrite. J. Clin. Invest., 1937, $16,85$.

22. Ellis, L. B., and Haynes, F. W., Postural hypotension: with particular reference to its occurrence in diseases of the central nervous system. Arch. Int. Med. (In press).

23. Schellong, F., and Heinemeier, M., Über die Kreislaufregulation in aufrechter Körperstellung und ihre Störungen. I. Ztschr. f. d. ges. exper. Med., 1933, 89, 49.

24. Turner, A. H., Newton, M. I., and Haynes, F. W., The circulatory reaction to gravity in healthy young women. Evidence regarding its precision and its instability. Am. J. Physiol., 1930, 94, 507.

25. Jokl, E., Die Sportkrankheit. Klin. Wchnschr., 1930, 9, 984.

26. Weltzien, G., UUber den Einfluss von Muskelarbeit auf die Magensekretion mit besonderer Berücksichtigung der Magenbeschwerden bei kurzdauernder anstrengender Arbeit. Arbeitsphysiol., 1933, $7,150$.

27. Mateeff, D., and Petroff, C., Gravitationsshock beim Menschen nach Muskelarbeit. Ztschr. f. d. ges. exper. Med., 1932, 85, 115.

28. Mateeff, D., Der orthostatische KreislaufkollapsGravitationsshock (gravity shock) - beim Menschen nach körperlicher Arbeit. Arbeitsphysiol., 1935, 8, 595.

29. Weiss, Soma, and Baker, J. P., The carotid sinus reflex in health and disease. Its rôle in the causation of fainting and convulsions. Medicine, 1933, 12, 2.97. 